Authors have nothing to disclose with regard to commercial support.

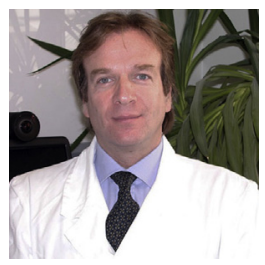

\section{NONCORONARY SINUS REPLACEMENT IN BICUSPID VALVE: THE OTHER FATE?}

\section{To the Editor:}

We read with interest the article by Milewski and colleagues, ${ }^{1}$ which demonstrated that supracoronary ascending aortic replacement in patients with concomitant aortic valve disease (either insufficiency or stenosis) may positively affect aortic root fate in the long term ( $\geq 10$ years of follow-up) irrespective of valve morphology (bicuspid or tricuspid aortic valve).

Nevertheless, Milewski and colleagues ${ }^{1}$ did not mention the role of the ascending aorta replacement extended to the noncoronary sinus (NCS), which in our experience ${ }^{2}$ as well as in that of others ${ }^{3}$ represents a valid surgical option, especially in patients with right-to-left cusp fusion and isolated NCS dilation.

In particular, our approach has been shown to provide excellent, durable clinical results and to avoid surgical risks related to mobilization and reimplantation of coronary ostia (typically faced during Bentall and valve-sparing procedures); from a practical standpoint, it has also been shown to be less demanding and to be less time-consuming than other mentioned techniques. The study of Milewski and colleagues ${ }^{1}$ describes comparable results for bicuspid and tricuspid aortic valve groups in terms of postoperative dimensions of the sinuses of Valsalva and 10-year freedom from reoperation $(P=.576)$. As is well known, bicuspid aortic valve is a heterogeneous disease, with a genetic etiologic component. Bicuspid aortic valve involves not only the valve's leaflets but also the aortic wall (including the sinuses of Valsalva), even if it does not appear macroscopically dilated. Presence of a bicuspid valve, especially if the right and the left coronary cusps are fused, is known to be associated with

\footnotetext{
The Editor welcomes submissions for possible publication in the Letters to the Editor section that consist of commentary on an article published in the Journal or other relevant issues. Authors should: • Include no more than 500 words of text, three authors, and five references. $\bullet$ Type with double-spacing. • See http://jtcs.ctsnetjournals.org/ misc/ifora.shtml for detailed submission instructions. • Submit the letter electronically via jtcvs.editorialmanager.com. Letters commenting on an article published in the JTCVS will be considered if they are received within 6 weeks of the time the article was published. Authors of the article being commented on will be given an opportunity of offer a timely response ( 2 weeks) to the letter. Authors of letters will be notified that the letter has been received. Unpublished letters cannot be returned.
}

asymmetric aortic root dilation (probably from anomalous hemodynamic flow, shear stress patterns, and a histological phenotype with an excess of collagen fibers surrounding coronary ostia), first involving the NCS, which represents the most common site of intimal disruption and flap formation, and ultimately leading to aortic dissection, ${ }^{4,5}$

On the basis of this pathophysiologic evidence, and considering safety and feasibility of the surgical technique, we note the importance of NCS replacement during ascending aortic or bicuspid aortic valve replacement, including cases with "apparently" normal root, to prevent further aortic dilation and dissection.

In addition, we recognize that a larger cohort study, with a longer follow-up, comparing ascending aorta replacement extended to NCS with supracoronary sinus replacement is mandatory for a better understanding of the aortic root remodeling process in the long term.

In conclusion, we believe that isolated removal of NCS should be considered in patients undergoing ascending aortic replacement and in the setting of bicuspid aortic valve (with or without aortic valvulopathy requiring surgery and certainly in those with asymmetric sinus of Valsalva dilation). It further stabilizes the aortic root, prevents the aortic root's gradual and predictable dilation, and therefore reduces the need for late reoperation for aneurysmal recurrence.

Nicola Pradegan, $M D$ Assunta Fabozzo, MD

Gino Gerosa, MD

Cardiac Surgery Unit

Department of Cardiac, Thoracic, and Vascular Sciences University of Padua Medical School Padua, Italy

\section{References}

1. Milewski RK, Habertheuer A, Bavaria JE, Siki M, Szeto WY, Krause E, et al. Fate of remnant sinuses of Valsalva in patients with bicuspid and trileaflet valves undergoing aortic valve, ascending aorta, and aortic arch replacement. J Thorac Cardiovasc Surg. 2017;154:421-32.

2. Gerosa G, Pontarollo S, Iliceto S, di Marco F. An alternative technique for aortic root remodeling in patients with bicuspid aortic valve. J Thorac Cardiovasc Surg. 2007;133:249-50.

3. Ugur M, Schaff HV, Suri RM, Dearani JA, Joyce LD, Greason KL, et al. Late outome of noncoronary sinus replacement in patients with bicuspid aortic valves and aortopathy. Ann Thorac Surg. 2014;97:1242-6.

4. Peterss S, Bhandari R, Rizzo JA, Fang H, Kuzmik GA, Ziganshin BA, et al. The aortic root: natural history after root-sparing ascending replacement in nonsyndromic aneurysmal patients. Ann Thorac Surg. 2017;103:828-33.

5. Elefteriades JA, Peterss S, Nezami N, Gluck G, Sun W, Tranquilli M, et al. V-shape noncoronary sinus remodeling in ascending aortic aneurysm and aortic root ectasia. J Thorac Cardiovasc Surg. 2017;154:72-6.

https://doi.org/10.1016/j.jtcvs.2017.09.096 